\title{
LA FORMACIÓN LÉXICA REGIONAL HISPANOAMERICANA
}

El proceso de creación del léxico regional hispanoamericano comenzó en los días mismos del descubrimiento, por la necesidad que sintieron Colón y sus compañeros de encontrar voces nuevas que correspondieran a la nueva naturaleza y a las nuevas costumbres e instituciones con que se iban topando. La propiedad de la denominación fué un verdadero problema, como puede verse por varios pasajes del Diario del Almirante ${ }^{1}$. A veces descubre, como con un suspiro de alivio, animales y plantas a los que puede aplicar, con alguna certeza, nombres europeos ${ }^{2}$; pero siempre quedan dudas: en Cuba decide llamar perdices a las de la tierra, vacilando en cuanto a la propiedad de ese nombre, pues las encuentra demasiado pequeñas. En este primer vocabulario -linaloe, palmas, faxones y fabas, algodón, perdices, papagayos, y además lagartos, sierpes y algunos otros- podemos ver una primera solución al problema planteado por la nueva realidad americana.

El deseo de la propiedad lingüística y la consiguiente indecisión para dar nombres a las cosas que no pueden reconocer se complica en el ánimo de los descubridores con el prejuicio de hallarse cerca de las tierras visitadas y descritas por Marco Polo. En el Diario, desde fecha muy temprana ( 17 de octubre), Colón habla ya de "estas Indias", y poco después supone que las voces Cibao y Caribe, oídas a los aborígenes, son equivalentes de Cipango y Caniba o tierras del

1 Así, el 17 de octubre de 1492 anota Colón: "algunos árboles eran de la naturaleza de otros que hay en Castilla, por ende [=porém 'pero'] habia muy gran diferencia, y los otros árboles de otras maneras eran tantos, que no hay persona que lo pueda decir ni asemejar a otros de Castilla". El día 21 vió tales bandadas de papagayos "que oscurecen el sol, y aves y pajaritos de tantas maneras y tan diversas de las nuestras, que es maravilla; y después hay árboles de mil maneras, y todos de su manera y fruto, y todos huelen que es maravilla, que yo estoy el más penado del mundo de no los cognoscer".

2 E1 21 de octubre ve Colón "gran cantidad de palmas de otra manera que las de Guinea y de las nuestras"; el 23 de octubre ve "mil maneras de yerbas.... y de todo no se conoció, salvo este liñaloe"; el 4 de noviembre dice que las tierras que va descubriendo son muy fértiles y que los naturales las tienen sembradas de "faxones y fabas muy diversas de las nuestras y mucho algodón..., y otras mil maneras de frutas que no me es posible escribir". 
Gran Can, en una de cuyas islas, según Marco Polo ${ }^{3}$, vivía cierta mala gente "que comen a todos los hombres que pueden apresar". Ese mismo prejuicio le hace creer que Luis de Torres, marinero que sabía árabe, le puede servir de intérprete, puesto que los árabes musulmanes habían precedido a los cristianos en ese remoto Oriente. Así se explica la inclinación por las voces árabes para nombrar las cosas nuevas: la canoa es almadia, los indios son gandules, azagayas sus armas, alfaneques sus casas y alcatraz el pelícano americano. Por la misma razón los descubridores llaman canelos, pimientos, clavos, etc., a árboles y plantas que ven por vez primera. También aquí hay cierto afán de propiedad, y así se da el nombre de panizo al maíz, pues nadie duda de que se trata de la gramínea oriental llamada panizo por los viajeros españoles que habían llegado hasta el Mediterráneo levantino, donde su empleo era conocido ${ }^{4}$. Y los pobres caciques reciben el nombre de reyes, reproducción de la idea que de los reyezuelos orientales tenían los europeos según una tradición que se remonta a las guerras de Alejandro.

Cuando se reconoce que "estas Indias" no son las orientales, el vocabulario toma un rumbo definidamente "americano"; se adopta gran número de voces indígenas para designar lo autóctono, y el habla de conquistadores y pobladores se tiñe de exotismo. El número de indigenismos debió de ser bastante elevado en la lengua hablada en los primeros tiempos. Oviedo recoge en su Historia más de cuatrocientos cincuenta. Pero este modo de expresión tenía el inconveniente de ser ininteligible para quienes no estaban familiarizados con la nueva realidad, de modo que hubo que traducir, con mayor o menor acierto, las voces americanas. Se puede recoger así un nutrido repertorio de equivalencias, como aji y pimienta, caimán y lagarto, iguana y sierpe, naboria y esclavo, cacique y señor, guanin y oro bajo, etc. Las traducciones no siempre satisfacían a todos: iguana se traduce después por 'lagarto' y no por 'sierpe', y caimán por 'cocodrilo' y no por 'lagarto'. Oviedo propone que, ya que se ha de traducir caimán, no sea por 'cocodrilo', fundamentalmente distinto del caimán para su ojo de naturalista, sino por el latinismo 'cocatriz', y que tampoco se traduzca ochi (animal de Honduras) por 'tigre', porque esto induciría a engaño.

${ }^{3}$ La isla de Angaman (cf. Marco Polo, 11 millione, ed. Luigi Foscolo Benedetto, Firenze, 1928, cap. CLXXIII).

${ }^{4}$ La ilusión de estar en el Oriente perdura muchos años. En mayo de $15^{\circ}{ }^{\circ}$, visitando las costas de Veragua, Colón cree estar a diez jornadas del Ganges y llama almaizares a los taparrabos de los indios, almafalas a las mantas con que se cubren las mujeres y adalides a los indios guías. (Carta de Colón a los Reyes, fechada en Jamaica el 7 de julio de ${ }_{15}^{\circ}$; ; cf. también Las Casas, Historia de las Indias, III, $\mathbf{x X}$ ).

"Las Casas, op. cit., III, xxir, dice que en cierto río de Cuba "se crían infinitos crocodilos que abusivamente llamamos lagartos". 
La demora de un cuarto de siglo de los españoles en las Antillas antes de emprender la conquista del continente favoreció la unificación de las denominaciones, puesto que los nombres impuestos por los primeros pobladores se trasmitieron a los posteriores ${ }^{6}$. Pero en Tierra Firme había muchas cosas desconocidas en las Antillas, y para ellas había que encontrar nuevos nombres. Se desarrollan entonces otros recursos más decididamente creadores, como los de derivación y composición y los descriptivos y metafóricos; se ensayan traducciones sucesivas hasta dar con una que se mantiene más o menos firme. El recurso más espontáneo es el de la analogía: el pavo se llama primero gallina, luego gallina de la tierra, luego gallo de papada y finalmente pavo; al conocido cathartes aura o tiñoso de las Antillas se le llama cuervo en el Paraguay, gallinazo en Colombia y el Perú, buitre en Bolivia ${ }^{7}$, atendiendo respectivamente al color, a la supuesta semejanza y a las costumbres de esta ave de rapiña; el tapirus ame. ricanus recibió los nombres de anta, gran bestia, ante, anteburro; al monito hoy conocido por titi unos llamaron gato, otros monillo, Oviedo lo llama gato monillo, mientras en el diario de Pigafetta, muy influído por el vocabulario "americano" de los españoles, se le llama leoncillo: cada grupo, o cada individuo, ve las semejanzas desde ángulos distintos.

Pero este procedimiento acarrea un peligro: el de aplicar el mismo nombre a cosas o animales muy diferentes, sin más relación entre sí que algún leve denominador común. Los ejemplos de fauna y flora abundan. ¿A cuántas aves se da el nombre de cuervo en Hispanoamérica?8 ¿Y cuántos de esos "cuervos" se asemejan al cuervo europeo en algo más que en el color? Por ejemplo, en la Pampa se llama cuervo un ave acuática llamada bandurria en Bolivia y en otras partes de la misma Argentina. ¿Cuántos pájaros reciben el nombre de urraca? ¿Cuántas flores reciben el de amapola, y por qué? ${ }^{3}$

- "Los españoles que fueron a conquistar el Perú, como en todas las palabras y cosas generales y más comunes iban amostrados de los nombres en que las Ilamaban de las islas de Santo Domingo y San Juan y Cuba y Tierra Firme donde habían vivido, y ellos no sabían los nombres en la lengua del Perú, nombrábanlas con los vocablos que de las tales cosas traían aprendidos, y esto se ha conservado de tal manera, que los mismos indios del Perú cuando hablan con los cristianos nombran estas cosas generales por los vocablos que han oído dellos" (Agustín de ZÁrate, Historia del descubrimiento y conquista de la provincia del Perú, en BAAEE, vol. XXVI, pág. 470b).

7 Otros nombres americanos de origen español son chul8 y carranco, pero el ave tiene además muchos nombres indígenas (zopilote, zamuro, urubú, etc.).

${ }^{8}$ L.As Casas, op. cit., I, Xcvi, habla de cuervos marinos.

${ }^{\circ}$ Las Casas, op. cit., I, XcV, dice que los españoles que acompañaban a Colón vieron en Cuba "unas aves como grullas coloradas"; pero luego rectifica: "estas aves no son grullas, sino de la misma manera y tan grandes como grullas, excepto que son al principio blancas ... y poco a poco [con la edad] se van tornando coloradas". Evidentemente, el nombre no le parecía apropiado.-Robolfo 
Menos peligroso es el procedimiento de formar, por analogía, un derivado de un nombre español. En el caso del gallinazo, el supuesto parecido de esta ave con la gallina origina el nombre, cuya desinencia alude, sin embargo, a las desemejanzas. Aceitunillo es en las Antillas un árbol de madera dura, pero de fruto venenoso. Aguilucho es en la Argentina un falcónido pequeño, distinto del que lleva el mismo nombre en Chile y en Centroamérica.

Tal como ocurrió con el titi o con el pavo, el procedimiento descriptivo originó múltiples designaciones para un mismo objeto. En los pájaros, por ejemplo, se atendió a su color, a sus hábitos, a su forma. El caráu o plegadis guaraúna se llama cuervo en algunas partes, cuervo de cañada en otras, y en otras bandurria y viuda loca. Rabihorcado llama Oviedo ${ }^{10}$ al ave que otros llamaron tijereta: las dos denominaciones se fijan en la cola de este pájaro, pero la primera es más descriptiva y la segunda más metafórica. El hornero es un ave que se llama así en Bolivia, Buenos Aires y el Uruguay, pero casero en Tucumán y Entre Ríos, aloncito en Corrientes y Alonso Garcia en el Paraguay: hornero y casero son nombres que describen el hábito de hacer el nido de barro, pero en hornero se atiende además, o principalmente, a la forma del nido; aloncito es también nombre descriptivo, referido al tamaño del alón de esta ave, o quizá a su aletear, que se dice ser "muy cómico"11; en el Paraguay se toma aloncito por diminutivo de Alonso, y se añade el apellido Garcia por un soldado de cierta fama, Alonso García, que con motivo de las guerras civiles peruanas de mediados del siglo xvi se refugió en el Paraguay. También hay que mencionar el pájaro mosca, nombre recibido por esta avecita en el siglo XvI, y que luego entró en competencia con picaflor, chupaflor, chupamirto, chuparro$s a$, besaflor, que aluden a su hábito característico, y con tente en el aire, tominejo, burrión (<gorrión), zumbador, resucitado y otros que se refieren a su tamaño y a sus costumbres.

Un caso que ilustra la incesante creación de nombres es el del armadillo, llamado así por los primeros pobladores por analogía con

LENZ (prólogo al Dicc. etimológico de las voces chilenas ..., Santiago de Chile, 1905-1910) vió con mucha claridad este problema: "sería interesantísimo -diceaveriguar en las palabras de origen castellano... qué significan en cada uno de los países americanos y por qué se transfirió tal nombre"; critica a los diccionarios castellanos "que hasta ahora apenas han tomado nota de tales significados nuevos"; el Dicc: Acad. "da descripciones de muy dudoso valor, y los lexicógrafos americanos, con escasas excepciones, tampoco se han fijado en estas voces: como si no fuera un asunto mucho más grave para la unidad del lenguaje el atribuir distinto significado a una palabra conocida que introducir una nueva vo\%. con nueva idea!"

${ }^{10}$ Y también Juan de Castellanos (BAAEE, vol. IV, pág. $\left.76 b\right)$.

11 T. Saubidet, Vocabulario y refranero criollo, Buenos Aires, 1945, s. v. hornero. 
la armadura de los caballos de guerra, pero que bien pronto comenzó a tomar, aquí y allá, otros igualmente descriptivos, como mulita, bola, bolita, peludo, peludo grande, canasta, topo acorazado, Juan callado, además de algunos híbridos e indígenas. Al perderse la costumbre de acorazar a los caballos, dejó de haber razón para llamar armadillo a un animalito que, por otra parte, es tan tímido y tan desprovisto de medios de defensa. Así también al tucán se le conoció en Venezuela, en tiempos de Oviedo y de Castellanos, con los nombres descriptivos pia poco, pico de frasco, pico de canoa, pico feo y pito real (los conquistadores más antiguos, aludiendo también al descomunal tamaño del pico, lo habían llamado alcatraz). Entre muchos otros nombres descriptivos podemos mencionar los del tipo lobo marino, oso hormiguero, cardo fructifero, araña gato, ataja camino, quiebra hacha, barba de ángel, amiga de noche, bandera española, etc., tan abundantes en la fauna y la flora, y los del tipo zancudo, mochilera, perezoso, afrechero, armado, boyerito, arenero, burlón, campanero, etc., etc.

Otra de las fuerzas que obran aquí es la de la metáfora. Así, uno de los primeros nombres que tuvo el tucán fué el de predicador (pues un buen predicador tiene "buen pico", "mucho pico"). Claro que el proceso metafórico, como obra de la fantasía, no siempre es fácil de rastrear, de modo que muchos nombres pueden parecer simplemente caprichosos; por ejemplo, hay peces llamados tiñoso, $\mathrm{An}$ tonino, barbero, caballerete, catalineta, escribano, etc., y plantas llamadas burro, cabrón, candelero, capitana, amor seco, Adonis blanco, aquilón, etc. Hay, además, los nombres humorísticos: el tucán se llama Dios te dé ("pico", se entiende) en ciertas regiones de Venezuela, y en muchas partes se designa al perezoso con el nombre de Perico ligero.

La creación del vocabulario no se limitó, por supuesto, a la fauna y la flora. Todos los modos de la vida americana nos ofrecen testimonios a este respecto ${ }^{12}$, pero uno de los de mayor interés lingüístico es el que se refiere a los trabajos mecánicos y a las ocupaciones técnicas. Lenz ha hecho notar ${ }^{13}$ que el vocabulario azucarero tucumano difiere de ingenio a ingenio según la procedencia de los técnicos que los instalaron. Si se compararan entre sí los vocabularios técnicos de la industria azucarera cubana con la peruana, o de la venezolana con la mexicana, etc., nos encontraríamos seguramente con grandes divergencias; y lo más interesante es que varían asimismo las voces que se refieren a los trabajos complementarios de la elaboración del azúcar, desde la preparación de la tierra para la siembra de la caña copioso.

12 EI léxico hispanoamericano de cocina y alimentación es singularmente

${ }^{13}$ Diccionario etimológico, op. cit., pág. 19. 
hasta la expedición del producto. Lo mismo ocurre en el campo de otro trabajo aún más antiguo, el de la minería, practicado o intentado en casi todas las latitudes. Pero las divergencias son resultado, no tanto de la incomunicación o de la exposición a diversas influencias extranjeras, sino más bien de la evolución incesante a partir del momento en que los españoles iniciaron estas industrias en América.

Es natural que no haya en los vocablos técnicos muchas discre. pancias, pues por una parte eran ya conocidos en España, de manera que podían pasar fácilmente a la lengua general, y por otra parte se vinculaban de alguna manera con la experiencia diaria de la mayoría de los colonos, como la agricultura y la ganadería. Pero aun aquí puede haber creaciones regionales más o menos antiguas. Por ejemplo, en el Ecuador se habla de una manta de papas, en Cuba y Santo Domingo de montones de yuca y batatas, en Honduras de un manchón de tabaco, en Venezuela de una tabla de maíz, en Tucumán de un tablón de caña, voces todas que significan 'sementera' o 'parcela sembrada'. Sería sumamente interesante recoger y comparar los diversos vocabularios técnicos regionales: el de la ganadería e industria del cuero en México, Venezuela y la Argentina, el de la platería en México y Bolivia, etc.

La explicación de cómo se ha ido formando esta abigarrada riqueza léxica se encuentra en la historia social de Hispanoamérica. Se sabe que los artesanos, sea por causa de las leyes coloniales, sea por el menosprecio en que se tenía el trabajo mecánico, casi nunca ejercían su profesión en estas tierras ${ }^{14}$. Pero como esos trabajos eran imprescindibles, su ejercicio quedaba en manos de oficiales improvisados, indios sobre todo, que no conocían el léxico profesional y tcnían que reinventarlo de acuerdo con sus necesidades, su conocimiento del oficio, su cultura, su dominio de la lengua, su forma interior del lenguaje. Así se da el hecho curioso de que en el vocabulario técnico se echa mano de la lengua general. Pensemos en la $\mathrm{cu}$ chara de los albañiles: el nombre de este instrumento lo conocen en España todos los albañiles y muchos que no lo son; en América lo ignoraron los mismos albañiles, y así lo llamaron simplemente cuchara (en el Perú se llama badilejo, nombre tomado asimismo de la lengua general): a la argamasa o mortero se le llama mezcla, vocablo demasiado genérico. Los ejemplos se podrían multiplicar fácilmente ${ }^{15}$.

Que también este tipo de vocabulario empezó a crearse desde los primeros tiempos de la colonia puede comprobarse por los raros

it Cif. por ejemplo las Casas, op. cit., I, cxx, y passim.

15 En el Diccionario de Malaret encuentro, por ejemplo, las voces siguientes de la lengua general que usadas en la minería adquieren significaciones especiales: achura, albricias, avio, barra, bollo, bonanza, capacho, criadero, chuza, derrotero, despintar, empalmar, estaca, lechuza, mandón, manta, muchacho, polvorilla, trapiche... 
capítulos en que los viejos cronistas describen la vida cotidiana de las nacientes poblaciones, por las correspondencias de los colonos con las autoridades, de los obispos con los reyes, las actas capitulares, los testamentos y los tratados especiales sobre medicina, minería, etc. Si en todo esto es exigua la cosecha, puede ser en cambio abundantísima para quien quiera recogerla en la vida misma, pues el léxico sigue vigente. Faltan en nuestros diccionarios regionales los materiales de esta clase, o aparecen en escasa medida, porque nuestros lexicógrafos aficionados se ocuparon hasta hace poco especialmente de lo pintoresco, o de lo que juzgaban anormal. Veamos algunos ejemplos. A la arracacha de los Andes se la llama en Venezuela y parte de Colombia apio, pero en los diccionarios sólo se encuentra arracacha o racacha, o sea que la atención a lo indígena prevaleció sobre el interés lexicográfico. Y lo curioso es que, en muchísimos casos, las voces indígenas de nuestros diccionarios están olvidadas desde hace siglos por los mismos indios, o nunca se usaron en la lengua española de América. El P. Pedro Lozano, en su Historia del Paraguay, Río de la Plata y Tucumán, dice del mburucuyá (o murucuyá, como trae el Dicc. Acad.): "el mburucuyá es el portento de las yerbas, la gracia de los prados ... ; llamámosle los españoles granadillo y con el nombre más piadoso flor de la Pasión" - dos nombres españoles a falta de uno. Y Azara dice refiriéndose a los bosques del Paraguay: "todos estos terrenos abundan de osos hormigueros o tamanduas, de leones, de tigres..."; ya en esos tiempos era materia de erudición saber lo que era un tamandúa, pero tamandúa aparece como vocablo vigente en el Dicc. Acad., porque está en todos los diccionarios de americanismos ${ }^{16}$.

Para tener una idea clara de la magnitud del esfuerzo de los primeros pobladores en la creación léxica habría que explorar también las lenguas indígenas que conservan huellas de su primer contacto con el castellano ${ }^{17}$. Tan sólo en el guaraní del Paraguay y de la Argentina podrían señalarse cientos de voces españolas relativas a la fauna y la flora cuyos equivalentes indígenas están totalmente olvi

${ }^{16}$ Esta anomalía arranca del prestigio de las ciencias naturales en los siglos Xviı y xIx. Los naturalistas usaron las voces indígenas para la correcta identificación de las variedades animales y vegetales: petunia, ananassa, cariama, suinda, bixa, tapirus, manihot, etc., y en las descripciones, como las del texto, por la necesidad de ser precisos. De aquí pasaron las voces a los diccionarios y a los libros escolares, de donde las tomó en algunos casos la lengua culta: es lo que ocurre en la Argentina con puma y jaguar, animales que, sin embargo, siguen siendo león y ligre para la mayoría.

${ }^{17}$ Cf. E. Nordensk jöld, "Deductions suggested by the geographical distribution of some post-Columbian words used by the Indians of South America", en Comparative Ethnological Studies, V (Göteborg, 1922). 
dados $^{18}$; y hasta en el vocabulario de los oficios y ocupaciones habituales de los indios hay incrustadas voces castellanas.

El esfuerzo creador no ha cesado en ningún momento. Continuamente se crean voces que reflejan los prejuicios, los modos de posesión del idioma y las formas de vida peculiares de la región. Si a la botella de cuerno en que llevaban el agua o la "giñebra" para las "travesías" la llamaron chifle los primeros gauchos, por su semejanza con el silbato del cómitre de las galeras, hoy sus nietos, agricultores de la Pampa, con un léxico heredado de la vida ganadera, hablan con naturalidad de maíces bayos o alazanes. Y además, el esfuerzo creador va reemplazando a los indigenismos cuando éstos pierden su virtud de sugerencia. En Tucumán, oreja de negro es nombre nuevo que va sustituyendo en boca de jóvenes al viejo nombre indio pacarí, y pavita de monte se aplica ahora al ave que los viejos llaman aún charata. En Venezuela, mucha gente llama ya palma real al vistoso chaguaramo, como en la Pampa la gente nueva le dice romerillo a lo que los antiguos gauchos daban el nombre de mio-mio. Y supongo que otro tanto ocurre en toda la América española.

University of Florida.

Marcos A. Morínigo

${ }^{18}$ Los españoles llamaron piña a la ananassa sativa, y este nombre desplazó a los indígenas regionales en toda Hispanoamérica. En el Brasil, el nombre guarani naná pasó al portugués y de allí a las demás lenguas europeas, al adquirir valor comercial la fruta. Pero en el Paraguay, la región guaraní por excelencia y donde todos hablan esa lengua, la fruta se llama únicamente piña. 